\title{
INDEX TO VOLUME 65
}

\section{RESEARCH ANNOUNCEMENTS}

Aronson, D. G. On the initial value problem for parabolic systems of differential equations, 310 .

Atiyah, M. F. and Hirzebruch, F. Riemann-Roch theorems for differentiable manifolds, 276.

Bagemihl, Frederick. Some propositions equivalent to the continuum hypothesis, 84 .

Bishop, Errett. Some theorems concerning function algebras, 77.

Block, H. D. and Marschak, Jacob. An identity in arithmetic, 123.

Borel, Armand. Fixed points of elementary commutative groups, 322.

Browder, William. The cohomology of covering spaces of $H$-spaces, 140.

Buck, R. C. A complete characterization for extreme functionals, 130.

Cairns, S. S. Circumscribed cubes in euclidean n-space, 327.

Carlitz, L. Some arithmetic properties of generalized Bernoulli numbers, 68.

Chandrasekharan, K. and Mandelbrojt, S. On solutions of Riemann's functional equation, 358.

Cohen, Eckford. An arithmetical inversion principle, 335.

Cohen, P. J. Homomorphisms and idempotents of group algebras, 120.

Crawley, Peter. The isomorphism theorem in compactly generated lattices, 377.

Edwards, D. A. On independent group characters, 352.

Epstein, Bernard and Schoenberg, I. J. On a conjecture concerning Schlicht functions, 273.

Feldzamen, A. N. A generalized Weyr characteristic, 79.

Floyd, E. E. and Richardson, R. W. An action of a finite group on an $n$-cell without stationary points, 73.

Glicksberg, Irving. See deLeeuw, Karel.

Graves, L. M. Extensions of the lemma of Haar in the calculus of variations, 319.

- A multiplier rule for a class of two-dimensional variational problems, 374.

Guggenheimer, H. An n-dimensional analogue of the Cremona-Clebsch theorem, 113.

Hermann, Robert. Secondary obstructions for fibre spaces, 5.

Hirzebruch, F. See Atiyah, M. F.

$\mathrm{Kac}, \mathrm{M}$. and Kesten, Harry. Correction to the note "On rapidly mixing transformations and an application to continued fractions," 67.

Kesten, Harry, See Kac, M.

Kister, James. Small isotopies in Euclidean spaces and 3-manifolds, 371.

Krabbe, G. L. Normal operators on the Banach space $L^{p}(-\infty, \infty)$. Part I. Bounded operators, 270.

deLeeuw, Karel and Glicksberg, Irving. Almost periodic compactifications, 134.

Loewner, C. and Netanyahu, E. On some compositions of Hadamard type in classes of analytic functions, 284.

McCarthy, C. A. On open mappings in Banach algebras, II, 66.

Mandelbrojt, S. See Chandrasekharan, K.

Marschak, Jacob. See Block, H. D.

Mazur, Barry. On embeddings of spheres, 59. 
Munkres, James. Obstructions to the smoothing of piercewise-differentiable homeomorphisms, 332 .

Narasimhan, M. S. A remark on curvature and the Dirichlet problem, 363.

Netanyahu, E. See Loewner, C.

Peleg, Bezalel. On the set of solvable n-person games, 380.

Pitcher, Everett. The variation in index of a quadratic function depending on a parameter, 355.

Plunkett, R. L. A topological proof of the continuity of the derivative of a function of a complex variable, 1.

Rhoades, B. E. Some structural properties of Hausdorff matrices, 9.

Richardson, R. W. See Floyd, E. E.

Rubin, Herman. A new form of the generalized continuum hypothesis, 282.

Schechter, Martin. General boundary value problems for elliptic partial differential equations, 70.

Schoenberg, I. J. See Epstein, Bernard.

Shapiro, V. L. The conjugate Fourier-Stieltjes integral in the plane, 12.

Shields, P. C. A new topology for von Neumann algebras, 267.

Spitzer, Frank. Some probability limit theorems, 117.

Swan, R. G. The homology of cyclic products, 125.

A new method in fixed point theory, 128.

Projective modules over finite groups, 368.

Groups with periodic cohomology, 365.

Wall, C. T. C. Note on the cobordism ring, 329.

Wright, E. M. Solution of the equation $z e^{z}=a, 89$.

\section{REPORTS OF MEETINGS AND MISCELLANEOUS ARTICLES}

Council and Board of Trustees-1958, 36.

Doctorates conferred in 1958, 170.

Green, J. W. and Pitcher, Everett. Reports of Meetings of the American Mathematical Society: The Annual Meeting in Philadelphia, 142; The April Meeting in New York, 258.

Huff, G. B. Reports of Meetings of the American Mathematical Society: The November Meeting in Durham, 95.

Meder, A. E., Jr. Report of the Treasurer, 17.

Pierce, R. S. Reports of Meetings of the American Mathematical Society: The November Meeting in Claremont, 94; The April Meeting at Monterey, 256; The June Meeting in Eugene, 300; The Summer Meeting in Salt Lake City, 347.

Pitcher, Everett. Reports of Meetings of the American Mathematical Society: The February Meeting in New York, 149.

- See Green, J. W.

Schafer, R. D. Reports of Meetings of the American Mathematical Society: The October Meeting in Princeton, 16.

Youngs, J. W. T. Reports of Meetings of the American Mathematical Society: The November Meeting in Evanston, 96; The April Meeting in Chicago, 255.

\section{BOOK REVIEWS}

Bade, W. G. See Dunford, Nelson.

Baldassarri, M. Algebraic varieties. H. T. Muhly, 306.

Bartle, R. G. See Dunford, Nelson. 
Boas, R. P., Jr. See de Bruijn, N. G.

See Margenau, Henry.

Boas, R. P., Jr. and Buck, R. C. Polynomial expansions of analytic functions. E. D. Rainville, 150.

Bodewig, E. Matrix calculus. J. L. Brenner, 109.

Boole, George. Calculus of finite differences, 35.

Brenner, J. L. See Bodewig, E.

Brownell, F. H. See Pinney, Edmond.

de Bruijn, N. G. Asymptotic methods in analysis. R. P. Boas, Jr., 160.

Buck, R. C. See Boas, R. P., Jr.

Carslaw, H. S. and Jaeger, J. C. Conduction of heat in solids, 308.

Chowla, S. See Walfisz, A.

Coddington, E. A. See Hurewicz, Witold.

Cohen, I. S. See Zariski, Oscar.

Cohn, P. M. Lie groups. Albert Nijenhuis, 338.

Collected papers of Professor R. Vaidyanathaswamy, 35.

Contributions to the theory of games, Vol. 3. Ed. by M. Dresher, A. W. Tucker and P. Wolfe. J. Wolfowitz, 101.

Contributions to the theory of games, Vol. 4. Ed by A. W. Tucker and R. D. Luce. J. Wolfowitz, 338.

Contributions to the theory of nonlinear oscillations, Vol. 4. Ed. by S. Lefschetz, 309 .

Davis, Martin. Computability and unsolvability. J. C. E. Dekker, 251.

Day, M. M. Normed linear spaces. F. Smithies, 344.

Dekker, J. C. E. See Davis, Martin.

Diaz, J. B. See Synge, J. L.

Dowker, Y. N. See Halmos, P. R.

Dresher, M. See Contributions to the theory of games, Vol. 3.

Dunford, Nelson and Schwartz, J. T. with the assistance of Bade, W. G. and Bartle, R. G. Linear operators. Part I: General theory. P. R. Halmos, 154.

Feinstein, Amiel. Foundations of information theory. S. Sherman, 301.

Field, G. See Pauli, W.

Forsythe, G. E. and Rosenbloom, P. C. Numerical analysis and partial differential equations. P. D. Lax, 342.

Franklin, Philip. Functions of complex variables. W. H. J. Fuchs, 307. See Kneser, Hellmuth.

Fuchs, W. H. J. See Franklin, Philip.

Goldberg, Samuel. Introduction to difference equations. D. E. Richmond, 111.

Goodman, J. E. See Kandau, E.

Grenander, Ulf and Szegö, Gabor. Toeplitz forms and their applications. F. Spitzer, 97. Hadwiger, H. Vorlesungen uber Inhalt, Oberflache und Isoperimetrie. T. Rad6, 20.

Halmos, P. R. Lectures on ergodic theory. Y. N. Dowker, 253.

- See Dunford, Nelson.

Harary, Frank. See Riordan, John.

Hartman, Philip. See Titchmarsh, E. C.

Hayman, W. K. Multivalent functions. J. A. Jenkins, 163.

Heins, A. E. See Tricomi, F. G.

Herstein, I. N. See Zariski, Oscar.

Hurewicz, Witold. Lectures on ordinary differential equations. E. A. Coddington, 25.

Jaeger, J. C. See Carslaw, H. S.

James, Glenn and James, R. C. Mathematics dictionary, 308. 
James, R. C. See James, Glenn.

Jenkins, J. A. See Hayman, W. K.

Kneser, Hellmuth. Funktionentheorie. Philip Franklin, 337.

Kreyszig, E. Differential geometrie. D. J. Struik, 108.

Landau, E. Elementary number theory. Trans. by J. E. Goodman, 35.

Lang, Serge. Introduction to algebraic geometry. M. Rosenlicht, 341.

Lax, P. D. See Forsythe, G. E.

Lees, Milton. See Lighthill, M. J.

Lefschetz, S. See Contributions to the theory of nonlinear oscillations, Vol. 4.

Lighthill, M. J. Fourier analysis and generalized functions. Milton Lees, 248.

Luce, R. D. See Contributions to the theory of games, Vol. 4.

Margenau, Henry and Murphy, G. M. The mathematics of physics and chemistry. R. P. Boas, Jr., 249.

Mordell, L. F. Reflections of a mathematician, 308.

Muhly, H. T. See Baldassarri, M.

Munroe, M. E. See Zaanen, A. C.

Murphy, G. M. See Margenau, Henry.

Myhill, John. See Suppes, Patrick.

Nagel, E. and Newman, J. R. Gödel's proof, 308.

Netanyahu, E. See Loewner, C.

Netto, E. Lehrbuch der Combinatorik, 35.

Newman, J. R. See Nagel, E.

Nijenhuis, Albert. See Cohn, P. M.

Numerische Mathematik, 309.

Osgood, W. F. Functions of real and complex variables, 35.

Oxtoby, J. C. See Sierpinski, W.

Pauli, W. Theory of relativity. Trans. from the German by G. Field, 308 .

Pinney, Edmond. Ordinary difference-differential equations. F. H. Brownell, 30.

Rad6, T. See Hadwiger, $H$.

Rainville, E. D. See Boas, R. P., Jr.

Richmond, D. E. See Goldberg, Samuel.

Riordan, John. An introduction to combinatorial analysis. Frank Harary, 166.

Rosenbloom, P. C. See Forsythe, G. E.

Rosenlicht, M. See Lang, Serge.

Samuel, Pierrre. See Zariski, Oscar.

Schwartz, J. T. See Dunford, Nelson.

Sherman, S. See Feinstein, Amiel.

Sierpinski, W. Cardinal and ordinal numbers. J. C. Oxtoby, 21.

Sikorski, Roman. Funkcje Rzeczywiste. Stanislaw Ulam, 305.

Smithies, F. See Day, M. M.

Spitzer, F. See Grenander, Ulf.

Struik, D. J. See Kreyszig, E.

Suppes, Patrick. Introduction to logic. John Myhill, 156.

Symposium internacional de topologia algebraica, 309.

Synge, J. L. The hypercircle in mathematical physics. J. B. Diaz, 103.

Szegö, Gabor. See Grenander, Ulf.

Titchmarsh, E. C. Eigenfuction expansions associated with second order differential equations, Part II. Philip Hartman, 151.

Traité des substitutions et des équations algébriques, 35 .

Tricomi, F. G. Equazioni a derivate parziali. A. E. Heins, 169. 
Tucker, A. E. See Contributions to the theory of games.

Ulam, Stanislaw. See Sikorski, Roman.

Vaidyanathaswamy, R. See Collected papers of Professor R. Vaidyanathaswamy.

Walfisz, A. Gitterpunkte in mehrdimensionalen Kugeln. S. Chowla, 23.

Wilanksky, Albert. See Zeller, K.

Wolfe, P. See Contributions to the theory of games, Vol. 3.

Wolfowitz, J. See Contributions to the theory of games.

Zaanen, A. C. An introduction to the theory of integration. M. E. Munroe, 110.

Zariski, Oscar and Samuel, Pierre with the cooperation of I. S. Cohen. Commutative algebra, Vol. 1. I. N. Herstein, 26.

Zeller, K. Theorie der Limitierungsverfahren. Albert Wilansky, 33.

\section{INVITED ADDRESSES}

Amitsur, S. A., 255.

Browder, Felix, 142.

Burgers, J. M., 142.

Coddington, E. A., 347.

Doob, J. L., 347.

Floyd, E. E., 95.

Henkin, Leon, 94.

Hirschman, I. I., 255.

Igusa, Jun-ichi, 258.

Iwasawa, Kenkichi. On F-extension of algebraic number fields, 183.

Lewy, Hans. On the reflection laws of second order differential equations in two independent variables, 37.

Lyndon, Roger, 96.

Lyndon, R. C. Properties preserved under algebraic constructions, 287.

Michael, E. A., 300.

Milnor, John, 258.

Mostow, G. D., 142.

Nash, John, 149.

Rudin, Walter. Measure algebras on abelian groups, 227.

Shapiro, Arnold, 16.

Smith, P. A., 347.

Taussky-Todd, Olga, 257. 